\title{
Orbital-scale variation in the magnetic content as a result of sea level changes in Papua New Guinea over the past 400 ka
}

Yin-Sheng Huang ${ }^{1,2^{*}}$, Teh-Quei Lee ${ }^{1}$ and Shu-Kun Hsu ${ }^{2}$

\begin{abstract}
We describe the orbital-scale environmental variation around Papua New Guinea (PNG) for the last 400 ka based on the environmental magnetism. Six magnetic parameters and the $\delta^{18} \mathrm{O}$ record of the core MD05-2928 are presented in the study. Results of magnetic analyses reveal opposite responses to different environmental conditions: Magnetic minerals were relatively fewer and finer in interglacial periods and were more and coarser in glacial periods. The reason could be suggested: In interglacial periods, sediments coming from central New Guinea were transported by the coastal currents in the northern Coral Sea and then imported to the core site location. Magnetic minerals would be relatively fewer and finer due to this longer transportation process. In glacial periods, the routes of the currents might regress seaward with reduced current intensity because of lower sea level. Main sediment sources would shift to the Papuan Peninsula relatively near the core site, and therefore, the magnetic minerals became more and coarser. Further, period analyses using the eccentricity, tilt, and precession (ETP) curves and the wavelet spectra were applied to the study to analyze the periodicities embedded in the parameters. Results of both period analyses clearly present the Milankovitch periods, indicating the dominance of the orbital forcing in this area. The strongest signal of 100-ka period reveals that sea level change played the dominant role in long-term environmental setting for the past $\sim 400 \mathrm{ka}$. However, influences of 40- and 20-ka periods, possibly related to regional precipitation, should also be considered though they might be second factors affecting the environmental variation around PNG.
\end{abstract}

Keywords: Papua New Guinea; Coral Sea; Wavelet analysis; Orbital forcing; Milankovitch cycles

\section{Background}

The Western Pacific Warm Pool (WPWP), with the average sea surface temperatures (SST) over $28{ }^{\circ} \mathrm{C}$ (Yan et al. 1992), is generally considered to be the global transported engine and important source providing water vapors. New Guinea, locating at the edge of the WPWP, is affected by several environmental factors, such as the intertropical convergence zone (ITCZ) migration, the Asian-Australian monsoon system, and the El-Niño Southern Oscillation (ENSO). Wind-driven currents and precipitation variation around the area are controlled by a biannual monsoon system. The ITCZ migration is proposed to be the driving force behind this biannual variability (Wang 2009). In austral summer, the ITCZ situates near/over northern

\footnotetext{
* Correspondence: yinson@earth.sinica.edu.tw

${ }^{1}$ Institute of Earth Science, Academia Sinica, Taipei, Taiwan

${ }^{2}$ Institute of Geophysics, National Central University, Chung-Li, Taiwan
}

Australia (Fig. 1), while in austral winter, the ITCZ shifts northward (Hobbs et al. 1998).

At the present day, New Guinea is politically divided into two portions, Irian Jaya in the west and Papua New Guinea in the east. Papua New Guinea (PNG), with the average precipitation about $2000-3000 \mathrm{~mm} \mathrm{a}^{-1}$ (McAlpine et al. 1983), is embraced by the Bismarck Sea, Solomon Sea, Coral Sea, and Arafura Sea (Fig. 1). Major rivers, coming from central New Guinea, receive input from rainfall and glacier meltwater, and then drain to the Gulf of Papua (GoP) (Brunskill 2004). These rivers deliver more than $\sim 365 \mathrm{mT}$ sediments per year to the GoP (Milliman 1995). Most detritus discharged by the rivers from New Guinea is stored on the inner shelf (Brunskill et al. 1995; Wolanski et al. 1995; Harris et al. 1996; Walsh et al. 2004; Keen et al. 2006). Only less than $5 \%$ of finer (suspended) sediments may be delivered eastwardly along the shelf by the coastal 


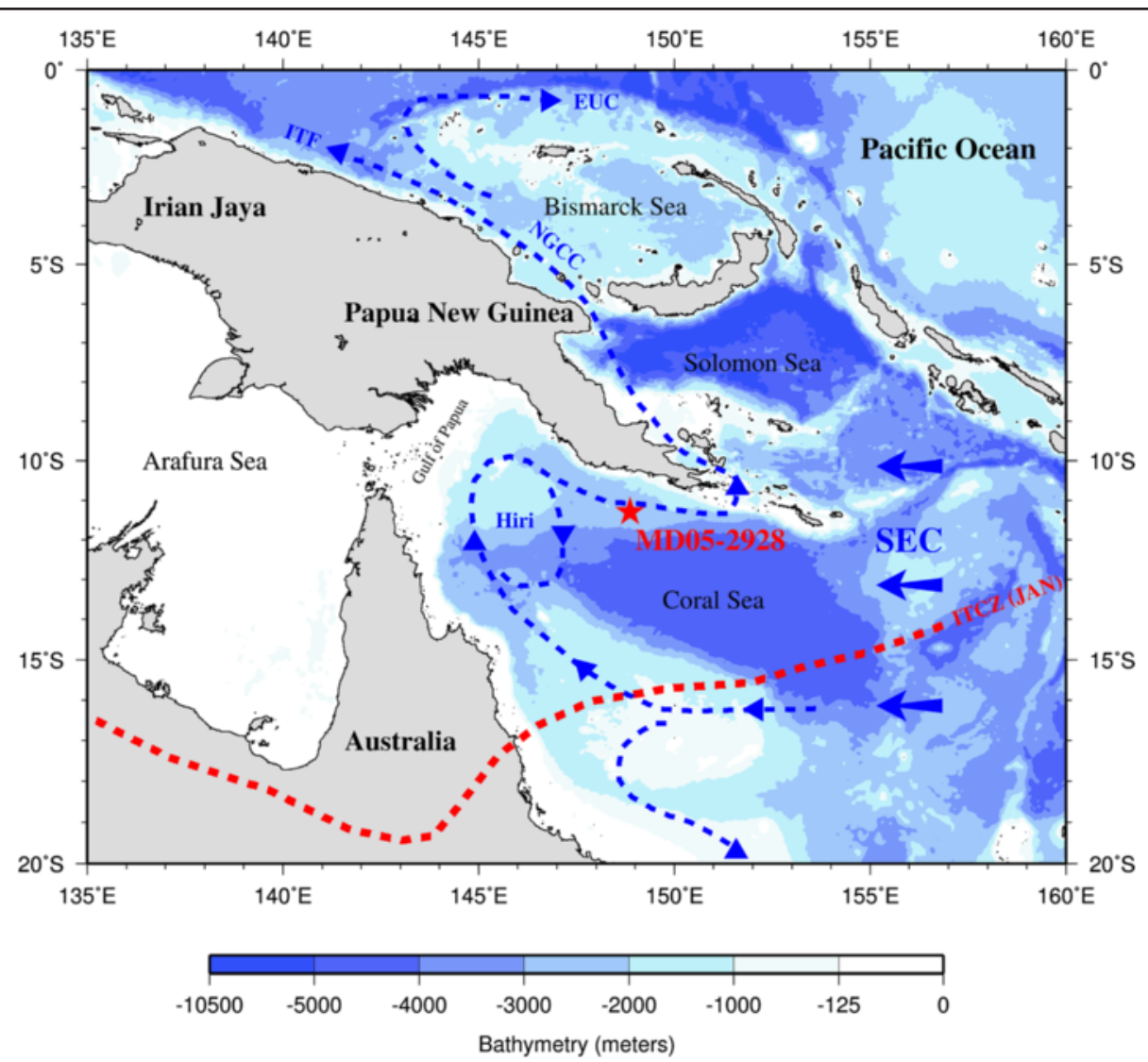

Fig. 1 Bathymetric map of the study area. The red star symbol is the location of the core MD05-2928. White areas show the regions shallower than $125 \mathrm{~m}$ water depth which may be above sea level in glacial periods. The red dashed line is the position of the ITCZ in austral summer. Blue dashed lines and arrows represent the ocean currents. SEC South Equatorial Current, Hiri Hiri current, NGCC New Guinea Coastal Current, ITF Indonesian Throughflow, EUC Equatorial Under Current

currents (Walsh and Nittrouer 2003; Muhammad et al. 2008). Shallower ocean currents are important in delivering the suspended sediments. Modern ocean currents around PNG are dominated by the global thermohaline circulation. The South Equatorial Current (SEC) inflows to the Coral Sea and forms a clockwise gyre named the Hiri Current in the northern Coral Sea (Fig. 1). Along the coast of New Guinea, the current then flows into the Solomon Sea and forms the New Guinea Coastal Current (NGCC). The maximum speed of this coastal current, lying near 200-300 $\mathrm{m}$ in water depth, is greater than $8 \mathrm{~cm} \mathrm{~s}^{-1}$ (Qu and Lindstrom 2002).

Evidences of recent glaciations, mostly observed in western New Guinea, are limited to vanishing glaciers only on higher mountains, but evidences of past glaciations are also observed in eastern PNG (Hastenrath 2009). In addition, during the Last Glacial Maximum (LGM), global sea level reached $\sim 125 \mathrm{~m}$ below the present sea level (Yokoyama et al. 2000; Clark et al. 2004; Bassett et al. 2005). Large portions of the Arafura Sea and the GoP would expose above sea level (Fig. 1), and river mouths would become relatively near to the shelf edge during glacial periods. Sediments transported from the land and the GoP to the Coral Sea should be significantly modified by the glaciations and sea level change.

In general, siliciclastic fluxes from the land to the slope in passive continental margin should be higher in major sea level lowstands and become lower during transgressions (Nelson 1990; Handford and Loucks 1993; Schlager et al. 1994). Past study in the Pandora Trough (nearby the GoP) has shown this similar property: Numerous siliciclastic turbidites were recorded in the LGM and Younger Dryas in the Pandora Trough, and extremely high accumulation rate was observed during 15,800-17,700 years (Febo et al. 2008). However, also nearby the GoP, some studies showed different flux features: Records of the siliciclastic fluxes from the Great Barrier Reef (GBR), Queensland Trough, and Ashmore Troughs were lower in lowstand periods and were higher during late transgression (Dunbar et al. 2000; Page et al. 2003; Carson et al. 2008). Therefore, sedimentary responses to sea level change would vary from one margin to another due to 
regional effects, such as the sediment supply, composition, and regional climate.

To understand more about the sedimentary response to sea level changes and the paleoenvironmental setting around PNG, a viewpoint from environmental magnetism is provided in the study. Magnetic parameters related to the environmental variation of the core MD05-2928 from southern offshore PNG were presented, including magnetic susceptibility $(X)$, anhysteretic remanent magnetization (ARM), saturated isothermal remanent magnetization (SIRM), $\chi_{\mathrm{ARM}} / \chi\left(\chi_{\mathrm{ARM}}\right.$, the ARM obtained in $0.1 \mathrm{mT}$ DC field within $100 \mathrm{mT}$ alternating field), SIRM $/ \chi, \chi_{\mathrm{ARM}} / \mathrm{SIRM}$, and S-ratio. Period analysis is further applied to the time series data to study the periodicities. Dominant periods embedded in these magnetic parameters and their relation to environmental variation can be understood based on these analyses.

\section{Methods}

\section{Materials and samples}

The Calypso core MD05-2928, taken from the slope of southern PNG in the northernmost Coral Sea (Lat. 11 ${ }^{\circ}$ 17.26' S, Long. $148^{\circ} 51.60^{\prime} \mathrm{E}$; water depth, $2250 \mathrm{~m}$; core length, $26.10 \mathrm{~m}$; Fig. 1), was obtained during the International Marine Past Global Change Study (IMAGES) PECTEN Cruise in 2005. Core sediments are composed of mixtures of biogenic carbonate and siliciclastic detritus (Beaufort et al. 2005). No visible turbidite or ash layer is found, and only minor biodisturbance is observed in the core. Therefore, the core could provide a suitable material for paleomagnetic study. Core sediments were sampled with $\mathrm{u}$-channels for paleomagnetic measurements. In total, $18 \mathrm{u}$-channel sections were obtained for the paleomagnetic study.

\section{Paleomagnetic experiment procedures}

All magnetic experiments of the study were performed in a magnetic shielding room. The interval of magnetic measurements, including the magnetic susceptibility, natural remanent magnetization (NRM), ARM, and IRM, were set to be $1 \mathrm{~cm}$. The magnetic susceptibility was first measured by using Bartington MS-2 magnetic susceptibility meter with a long core transporting system. Detailed alternating field (AF) demagnetization was then preformed by using 2G 755 SRM Superconducting Quantum Interference Device (SQUID) cryogenic magnetometer. In the study, the NRMs were measured at every $10 \mathrm{mT}$ interval from 0 to $100 \mathrm{mT}$ AF demagnetization along three orthogonal axes. The ARMs were acquired in a $0.1 \mathrm{mT}$ DC bias field within a $100 \mathrm{mT}$ alternating field simultaneously and then demagnetized by using AF demagnetization with an increment of 10 $\mathrm{mT}$ from 0 to $60 \mathrm{mT}$ field. Finally, the IRMs were induced along the $z$-axis by using a spiral coil impulse magnetizer at steps of $25,50,75,100,150,200,250$, $300,500,750$, and $950 \mathrm{mT}$ peak fields, and then, the samples were demagnetized and measured with the same procedure as for the ARM.

\section{Environmental magnetism}

Magnetic parameters such as magnetic susceptibility, SIRM, ARM, HIRM, S-ratio, $\chi_{\mathrm{ARM}} / \chi, \chi_{\mathrm{ARM}} / \mathrm{SIRM}$, and $\mathrm{SIRM} / \chi$, are often used in paleoenvironmental studies. These parameters have different environmental meanings based on their physical characteristics. In general, magnetic parameters could be roughly classified into three categories, representing variations of magnetic concentration, magnetic grain size, and magnetic mineralogy, respectively.

Magnetic susceptibility generally represents the concentration of all magnetic minerals while SIRM primarily relates to the change of RM carriers, such as magnetite and hematite (Opdyke and Channell 1996). Larger values of both parameters indicate more magnetic minerals in core sediments, and smaller values give an opposite situation. ARM is usually sensitive to the concentration of ferromagnetic minerals, but it is also strongly grain size dependent. ARM may decrease with increasing concentration due to interactions among magnetic particles (Sugiura 1979). In general, ARM preferentially responds to the concentration of finer grain $(<10 \mu \mathrm{m})$ magnetite (Opdyke and Channell 1996).

HIRM, the hard component of IRM, is derived from the formula: HIRM $=($ SIRM + bIRM $) / 2$, where the

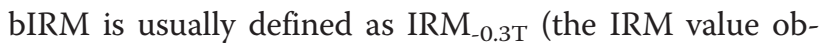
tained at $300 \mathrm{mT}$ back field). HIRM measures the concentration of the magnetic material with higher coercivity (e.g., hematite) and is often discussed together with the parameter S-ratio. S-ratio, generally defined as $\mathrm{IRM}_{-0.3 \mathrm{~T}} /$ SIRM, is associated with the change of magnetic mineralogy (Opdyke and Channell 1996). S-ratio close to one indicates the dominance of lower coercivity ferrimagnetic mineralogy (e.g., magnetite) while S-ratio decreasing away from one represents the increment of higher coercivity magnetic mineralogy (e.g., hematite).

The parameters $\chi_{\mathrm{ARM}} / \chi$ ( $\mathrm{X}_{\mathrm{ARM}}$ is the ARM obtained by applying $0.1 \mathrm{mT}$ DC field within $100 \mathrm{mT}$ AF field) and $\mathrm{SIRM} / X$ indicate changes in grain size of magnetic minerals dominated by magnetite. Both parameters vary inversely with magnetic grain size. $X_{\mathrm{ARM}} / X$ is sensitive to finer magnetic grains, particular in the ranges of single domain (SD) and pseudo-single domain (PSD), while $\mathrm{SIRM} / \chi$ responds more to larger (multi-domain, MD) grains (Opdyke and Channell 1996). In addition, for the grain size study, King et al. (1982) plotted the values of $X_{\text {ARM }}$ versus $X$ in a coordinate plane and obtained the ratio of $\chi_{\mathrm{ARM}} / X$ by using numerous magnetite samples with variety grain sizes. Based on the plot, they had proposed 
a convenient model to detect the change of magnetic grain size dominated by magnetite in natural magnetic materials.

In this study, the HIRM and S-ratio almost show a synchronously reverse pattern, implying that both parameters could offer similar information. Thus, only the S-ratio was adopted as the magnetic mineralogy proxy in the paper. Moreover, the $\mathrm{IRM}_{0.95 \mathrm{~T}}$ (the IRM value obtained at a peak field of $950 \mathrm{mT}$ ) was defined to be the SIRM in the study and the S-ratio was defined as $I R M_{-0.3 \mathrm{~T}} / \mathrm{IRM}_{0.95 \mathrm{~T}}$ due to the definition of the SIRM.

\section{Wavelet spectral analysis}

Wavelet transform of a time series signal $f(t)$ is defined as:

$$
W_{\psi}(f)(a, b)=\frac{1}{\sqrt{a}} \int_{-\infty}^{\infty} f(t) \psi\left(\frac{t-b}{a}\right) d t
$$

where $\psi(t)$ is the basis wavelet function with an effective length usually shorter than $f(t)$. The variable $a$ is the dilation/compression scale factor determining the characteristics frequency, and the variable $b$ shows the translation in time representing the shifting/sliding of the basis wavelet over the time series $f(t)$. Following the scheme of Chao and Naito (1995), we adopted the Morlet wavelet (Morlet et al. 1982), a normalized Gaussian-enveloped complex sinusoid with zero mean, as the basis wavelet function $\psi(t)$ in the study.

Wavelet spectrum, varying with the variables $a$ and $b$, is usually displayed in a time-frequency domain. The amplitude oscillation of a time series (variation between peaks and troughs) can be identified by using color contours. Higher contrast of the color indicates the presence of stronger oscillation while lower contrast shows weaker amplitude or background signals in the spectrum.

Some limitations of the scheme pointed out by Chao and Naito (1995) are as follows: The frequency resolution is limited to no better than a quarter octave because of the temporal localization of the wavelet. In addition, time series values outside the time span are simply assumed as zero and such step may bring edge effect to the spectrum, especially for longer periods. Details of the method and applications of the orbital forcing were discussed in the papers (Chao and Naito 1995; Liu and Chao 1998).

\section{Magnetic analysis and age control Magnetic properties of the core}

In the study, most S-ratio values are above 0.9 (Fig. 2a), and the IRM acquisition curves show that the IRMs almost situate at $300 \mathrm{mT}$ field (Fig. 2b). Both properties reveal that the magnetic minerals of the core should be dominated by magnetite. The parameter $\chi_{\mathrm{ARM}} / \chi$ therefore could be approximately considered to be the proxy describing the grain size variation of the magnetic minerals in the core. By applying the grain size model ( $\chi_{\mathrm{ARM}}$ versus $\chi$ ) established by King et al. (1982) to the study, the major grain size of the magnetic minerals is smaller than $0.1 \mu \mathrm{m}$ in this core (Fig. 2c). RM carriers of the core could be roughly determined to be dominated by SD and finer PSD magnetite.

Another notable feature is that several peaks rising over a relatively constant value of $\sim 8$ were recorded in the $X_{\text {ARM }} / X$ ratio (Fig. 3a). These peaks indicate the presence of finer magnetic minerals at these locations but may also indicate the contribution of magnetosomes. The magnetic materials of the core therefore appear to be consisted of dominant detrital input and minor biogenic origin. To clarify the issue whether magnetosomes existed in the core or not, some measurements were further applied to the study.

\section{Detection of magnetosomes}

To detect the magnetic properties of biogenic magnetite, Moskowitz et al. (1993) had proposed some magnetic criteria for biogenic magnetite after measuring several magnetic parameters. A convenient and useful parameter is the ratio, $\chi_{\mathrm{ARM}} / \mathrm{SIRM}$. High ratios of $\chi_{\mathrm{ARM}} / \mathrm{SIRM}$, ranging from 0.15 to 0.25 for an inducing field of 0.1 $\mathrm{mT}$, are a characteristic of the presence of magnetic bacteria (Moskowitz et al. 1993). In our study, some higher ratios (peak values) are found in both $\chi_{\text {ARM }} / X$ and $\chi_{\text {ARM }} /$ SIRM (the $\chi_{\text {ARM }}$ was also induced within a $0.1 \mathrm{mT}$ field), but almost all the $\chi_{\mathrm{ARM}} / \mathrm{SIRM}$ ratios are smaller than 0.15 (Fig. 3a, b). Only the peaks presented between 21 and $22 \mathrm{~m}$ core depth, with the maximum over 0.5, exceed this range (Fig. $3 \mathrm{~b}$ ). These peaks possibly imply the presence of magnetosomes between 21 and $22 \mathrm{~m}$ depth of the core.

However, high $\chi_{\mathrm{ARM}} / \mathrm{SIRM}$ ratios over this range are not only unique to biogenic magnetite but have also observed in rocks and sediments consisting of noninteracting SD particles (Moskowitz et al. 1993). To obtain a more direct proof, first-order reversal curves (FORC) measurements were further applied to detect the presence of magnetosomes (Pike et al. 1999; Roberts et al. 2000). FORC diagram is a convenient tool to identify the presence or absence of magnetostatic interactions and to identify the contributions to the magnetization of samples with different magnetic particles (Roberts et al. 2000). A single FORC measurement first applied a positive saturated field $\left(H_{s}\right)$ and then decreased to a reversal field $\left(H_{r}\right)$, and the magnetization is measured at each step of field $(H)$. FORC diagrams are generally plotted by using the transformed coordinates $H_{c}=\left(H-H_{r}\right) / 2$ and $H_{u}=\left(H+H_{r}\right) / 2$. 

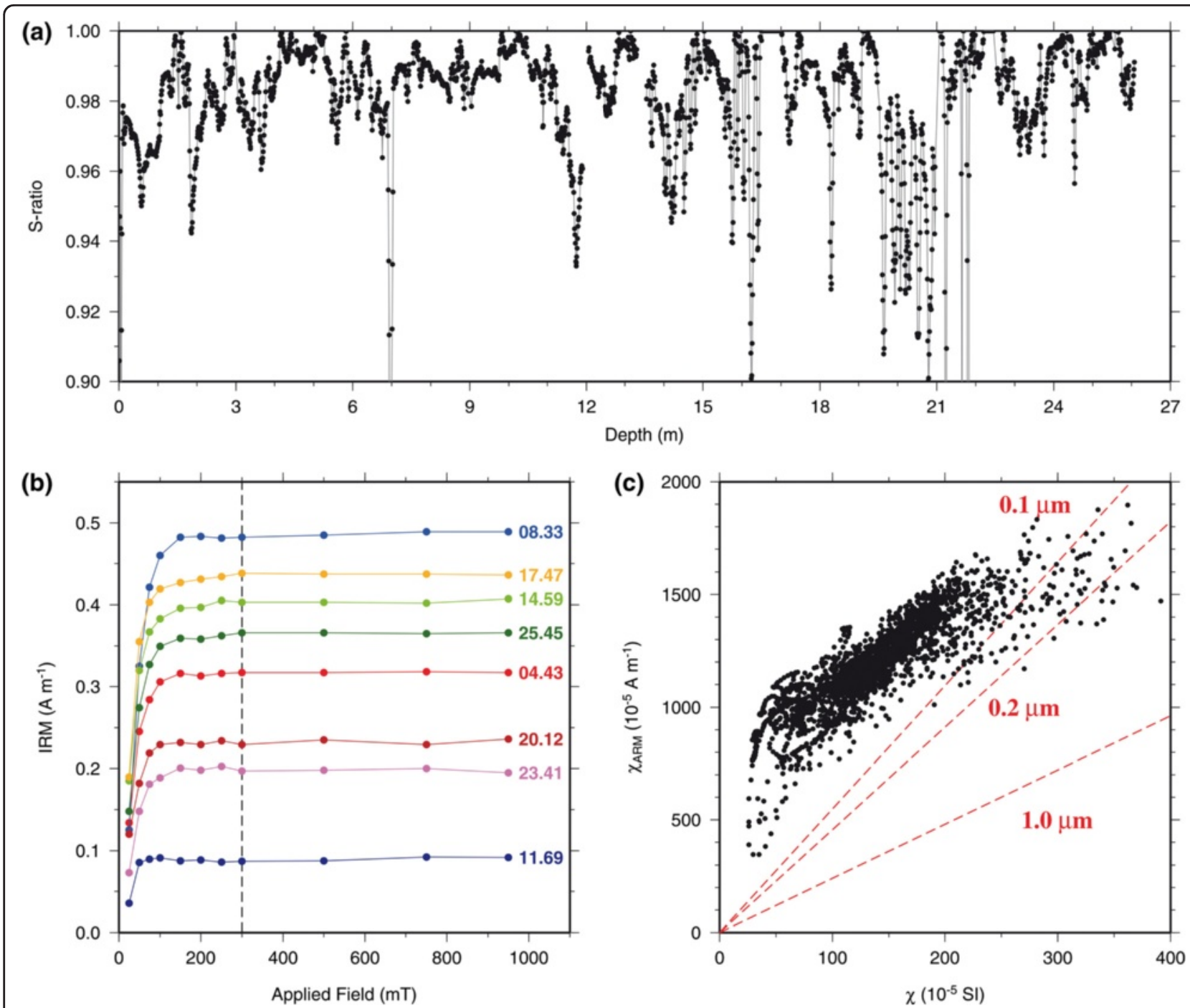

Fig. 2 a The S-ratio data of the core MD05-2928 (in depth). b The IRM acquisition curves of the studied samples. Lines and numbers with different colors represent the sampling depths (unit, $\mathrm{m}$ ), respectively. The black dashed line indicates the applied field at $300 \mathrm{mT}$. c The diagram of $X_{\text {ARM }}$ versus $x$ used to detect the grain size of the magnetic mineral dominated by magnetite. Red dashed lines and values show the grain size model (King et al. 1982)

High-precision FORC models have been well developed for several cases of magnetic particles. For uniaxial SD magnetite particles, FORC diagrams show a narrow ridge shape centered along the $H_{c}$ axis (Pike et al. 1999). This shape has never been observed in FORC diagrams of other magnetic particles, which may support that the narrow ridge shape is a unique feature of SD magnetite (Egli et al. 2010). For SD magnetite homogeneously diluted in a nonmagnetic matrix, FORC diagrams roughly show a teardrop shape with the center symmetric about the $H_{c}$ axis (Pike et al. 1999; Egli 2006). As for the coarser magnetic particles (PSD and MD dominance), FORC diagrams have a larger spread along the $H_{u}$ axis (Roberts et al. 2000).
Because magnetosomes usually synthesize chains of SD crystals with extremely well-controlled sizes and shapes (Egli et al. 2010; Heslop et al. 2013), a narrow ridge feature is expected to be presented in our FORC diagrams. We selected four samples for FORC measurements: At 0.59 and $6.91 \mathrm{~m}$ core depth, the two samples represented the locations where a higher peak value and a relatively constant value were recorded in the $X_{\mathrm{ARM}} / X$ and $\chi_{\text {ARM }} /$ SIRM ratios, respectively (Fig. $\left.3 a, b\right)$. At 21.21 and $21.81 \mathrm{~m}$ core depth, the two samples were selected because of two maximum values $(>0.5)$ presented in the $X_{\text {ARM }} /$ SIRM ratio (Fig. $3 \mathrm{~b}$ ), possibly denoting the presence of magnetosomes. For the FORC measurements, 150 FORCs were measured and a field spacing of $2 \mathrm{mT}$ was set, with coercivity $\left(H_{c}\right)$ between 0 and $120 \mathrm{mT}$, and 


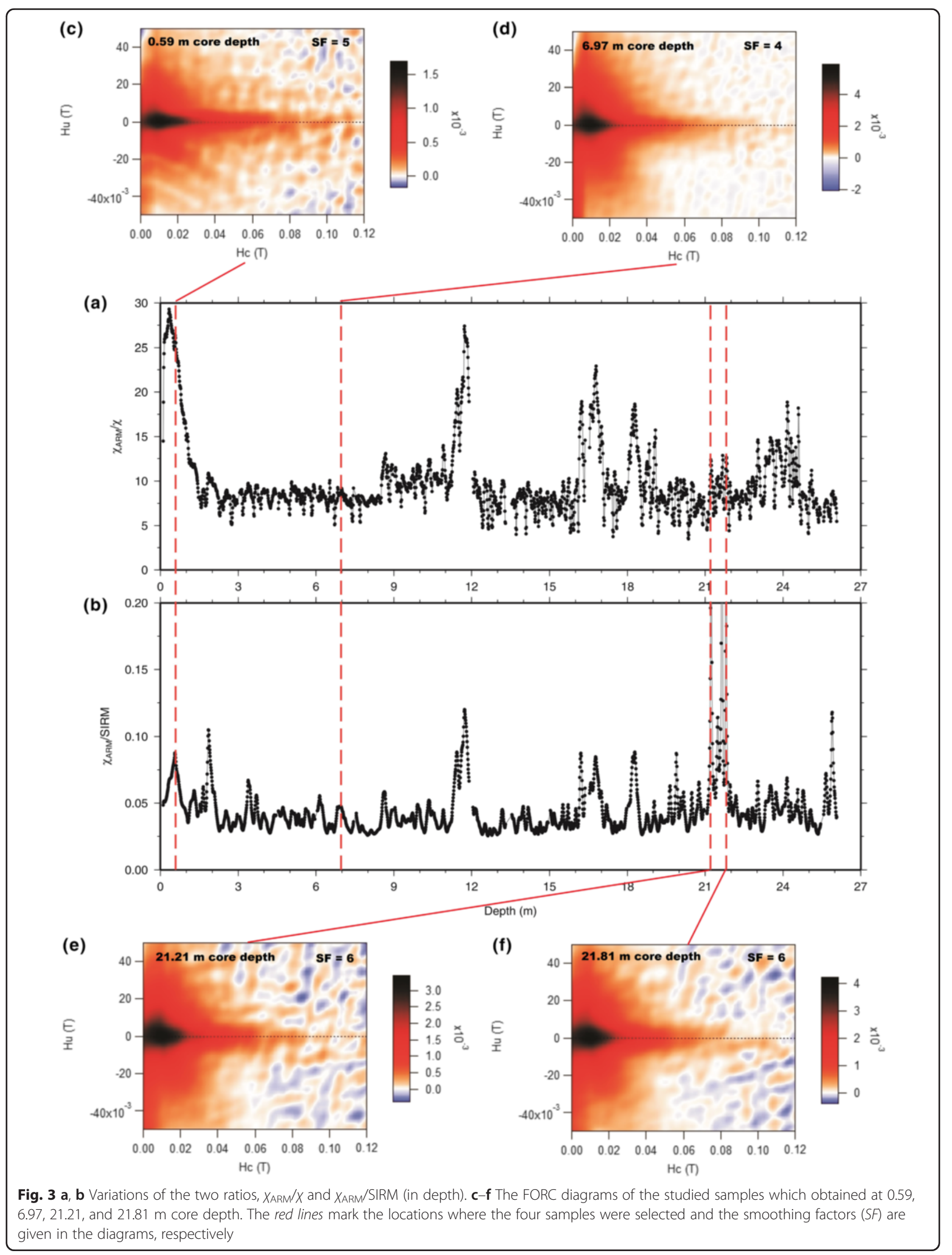


local interaction field $\left(H_{u}\right)$ between -50 and $50 \mathrm{mT}$. The FORCinel software (Harrison and Feinberg, 2008) was used for data processing, and smoothing factors (Roberts et al. 2000) of 4-6 were used.

As a result, instead of showing a narrow ridge shape, all the FORC diagrams present the feature with a stronger signal of a teardrop shape and a weaker signal of spread along the $H_{u}$ axis in the study (Fig. 3c-f). This feature indicates that the magnetic minerals of the core should be consisted of dominance SD and minor PSD magnetite. Because no feature of magnetosomes (a narrow ridge shape) is found in the FORC diagrams, no clear evidence reveals the presence of magnetosomes in the core. The effect of magnetosomes therefore would be ignored in further discussions.

\section{Relative paleointensity}

The use of evaluating relative paleointensity (RPI) relies on the reliability criteria established by King et al. (1983) and refined by Tauxe (1993). For a better RPI evaluation, Tauxe (1993) suggested that sediment magnetization should be carried by SD and PSD magnetite. In general, ARM, SIRM, and $\chi$ were adopted to normalize NRM to verify a best way in removing the effects from magnetic lithology. Tric et al. (1992) suggested that identical demagnetization treatment on NRM and ARM would offer the best information about magnetization carried by similar RM carriers. Based on the RPI evaluation, several stacks describing virtual axial dipole moment (VADM) have been reported (e.g., Guyodo and Valet 1999; Yamazaki and Oda 2005; Valet et al. 2005; Channell et al. 2009).

The RM carriers of the core are dominated by SD and PSD magnetite, suggesting a suitable material for RPI evaluation. For evaluating the RPI of the study, we first normalized the NRM by using the $\chi$, ARM, and SIRM. Both NRM and ARM were demagnetized after $20 \mathrm{mT}$ AF field, and the consistent in RM acquisitions for the studied demagnetization sequence was presented in the study. As a result, the three ratios, $\mathrm{NRM}_{20 \mathrm{mT}} / \mathrm{ARM}_{20 \mathrm{mT}}$, $\mathrm{NRM}_{20 \mathrm{mT}} / \chi$, and $\mathrm{NRM}_{20 \mathrm{mT}} / \mathrm{SIRM}$, all present a similar variation pattern (Fig. 4), and cross-correlation among the ratios also shows good correlation (coherence above 0.8 ). These properties indicate that all these ratios could offer similar information for the RPI evaluation. Following the suggestion of Tric et al. (1992), we adopted the ratio $\mathrm{NRM}_{20 \mathrm{mT}} / \mathrm{ARM}_{20 \mathrm{mT}}$ as the RPI proxy and then compared our RPI curve with the PISO-1500 stack (Channell et al. 2009) to get the RPI age control.

\section{Age control and age model}

The age model of the core was built by using the controlling points from the oxygen isotopic analysis, accelerator mass spectrometry (AMS) ${ }^{14} \mathrm{C}$ dating, and RPI dating. The RPI age control was obtained by correlating our RPI record to the PISO-1500 stack (Channell et al. 2009; Fig. 4). The $\delta^{18} \mathrm{O}$ record was analyzed by using the foraminiferal planktonic of Uvigerina spp. and Globigerinoides ruber. Then, the oxygen isotope curve was correlated to the LR04 stack (Lisiecki and Raymo 2005) to get the $\delta^{18} \mathrm{O}$ age control. The ${ }^{14} \mathrm{C}$ record, sampled from the upper part of the core, was obtained by using the planktic foraminifers Globigerinoides ruber and Globigerinoides saculifer and then sent to Tokyo University, Japan for AMS ${ }^{14} \mathrm{C}$ dating. Detailed information about the $\delta^{18} \mathrm{O}$ analysis and AMS ${ }^{14} \mathrm{C}$ dating was reported in the studies of Shiau et al. (2011) and Shiau et al. (2012).

In total, 29 controlling points were determined and used to build the age model in the study, including seven points of the RPI dating, 12 points of the $\delta^{18} \mathrm{O}$ analysis, and 10 points of the AMS ${ }^{14} \mathrm{C}$ dating (Table 1; Fig. 5). Based on the age model, the core MD05-2928, with $26.1 \mathrm{~m}$ in length, covers an age period about the last $400 \mathrm{ka}$, revealing an average sedimentation rate of $\sim 6.53 \mathrm{~cm} \mathrm{ka}^{-1}$.

\section{Results}

\section{Characteristics of the magnetic parameters}

After determining the age model, time series data of the study could be obtained (Fig. 6). Nine marine isotope stages (MIS) were first identified based on the $\delta^{18} \mathrm{O}$ record (Fig. 6a). Comparing the magnetic parameters with the $\delta^{18} \mathrm{O}$ record, variations of the magnetic parameters appear to be linked to the MIS change except the S-ratio record (Fig. 6). This property implies that the magnetic parameters could be roughly considered as proxies describing the environmental variation in the study.

Three magnetic proxies related to the concentration of magnetic minerals ( $\chi$, SIRM, and ARM) show a similar variation pattern: Relatively higher values (i.e., more magnetic minerals) and lower values (i.e., fewer magnetic minerals) are observed in glacial and interglacial periods, respectively (Fig. 6b-d). Many spikes are found in these proxies, especially in colder periods. These spikes could be roughly attributed to the increment of volcanic materials during glacial periods though there is no visible ash layer. Unlike typical cases of marine sediment cores, the magnetic susceptibility present higher values with an average about $150 \times 10^{-5}$ SI unit (Fig. 6b), which may also reveal the abundance of volcanic materials in the core. In contrast to the $X$ and SIRM, the ARM shows relatively constant variation over the entire period of time (Fig. 6d), implying the relatively constant input of finer magnetic particles over the past $400 \mathrm{ka}$ in the area.

For the proxies related to the magnetic grain size, the most notable feature is the sharp peaks recorded in MIS 7, MIS 5, and MIS 1 in the $\chi_{\mathrm{ARM}} / \chi$ ratio (Fig. 6e). These 


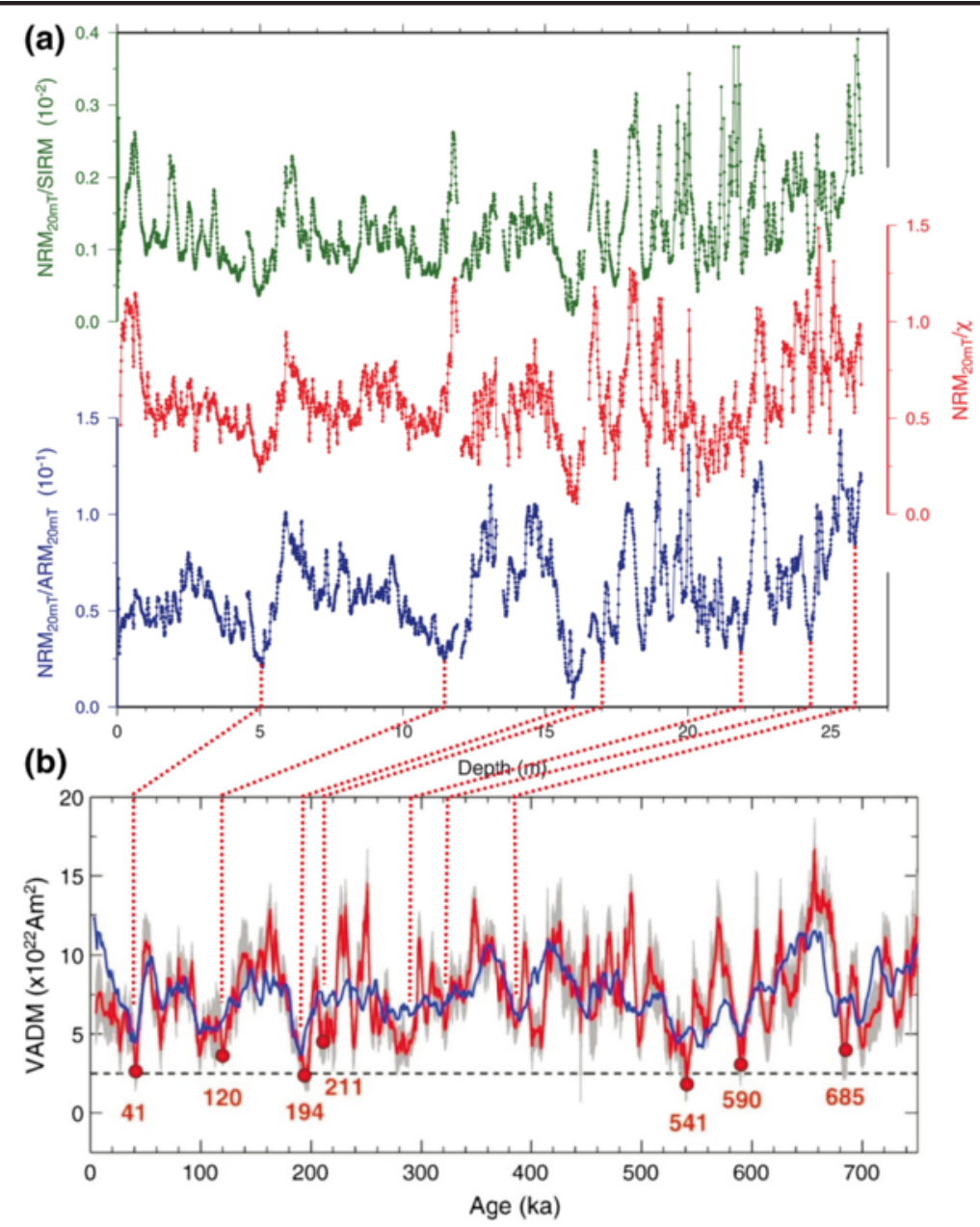

Fig. 4 a Three RPI estimation of the core (in depth): NRM $20 \mathrm{mT} / \mathrm{SIRM}$ in green, NRM $20 \mathrm{mT} / \mathrm{X}$ in red, and NRM $20 \mathrm{mT} / \mathrm{ARM}$ 20mT in blue. b The PISO-1500 stack (blue) and Sint-2000 stack (red) for the last $750 \mathrm{ka}$ (Channell et al. 2009). The black dashed line represents the threshold that appears to trigger excursions and reversals. Red dashed lines between up and down patterns correlate our RPI to the PISO-1500 stack

peaks rise over a constant value of $\sim 8 \mathrm{Am}^{-1}$ and occur systematically during the periods when the $X$ and SIRM are low (Figs. 6b, c). However, similar feature is not found in another grain size proxy, SIRM/ $\chi$ (Fig. 6f). These peaks therefore should be more related to the variation of $X$ and SIRM (magnetic mineralogy) rather than the change of the magnetic grain size. Except the peaks, both grain size proxies show simultaneous variation with the MIS change. Relatively lower values (i.e., coarser magnetic grains) are found in glacial periods and higher values (i.e., finer magnetic grains) are observed in interglacial periods (Fig. 6e, f).

As for the magnetic mineralogy proxy, the S-ratio values are almost greater than 0.9 (Fig. 6g), revealing the dominance of magnetic minerals with lower coercivity (e.g., magnetite) in the core. The notable peaks recorded in the $X_{\mathrm{ARM}} / X$ also synchronously show lower values in the S-ratio (Fig. 6e, g). This systematic variation could also give evidence that the peaks were induced by the change of magnetic mineralogy rather than the change of magnetic grain size. In addition, many low-value events appear to be recorded in cold periods and at MIS boundaries, but no clear correlation between the S-ratio variation and MIS change is observed.

\section{Period analyses}

To study the periodicities embedded in the environmental proxies of the core, we performed two period analyses: eccentricity, tilt, and precession (ETP) curves and wavelet spectra. Four proxies were selected for the period analyses, including the $\delta^{18} \mathrm{O}, X, \chi_{\mathrm{ARM}} \chi \chi$, and S-ratio. For the ETP analysis, we first filtered out the Milankovitch periods-eccentricity (100-ka period), tilt or obliquity (41-ka period), and precession (23-ka period)-from each of the proxies, respectively. Then, the ETP curves were composed of the three Milankovitch periods (Figs. 7a, 8a, 9a, and 10a). Further, considering the other periods out of the Milankovitch periods, the wavelet 
Table 1 Age model of the core MD05-2928

\begin{tabular}{|c|c|c|}
\hline Depth (m) & Age (ka) & Method \\
\hline 0.17 & 1.3 & AMS ${ }^{14} \mathrm{C}$ dating \\
\hline 0.72 & 5.0 & \\
\hline 1.12 & 8.4 & \\
\hline 1.62 & 12.5 & \\
\hline 1.87 & 15.3 & \\
\hline 2.12 & 16.8 & \\
\hline 2.37 & 18.8 & \\
\hline 2.72 & 20.7 & \\
\hline 3.47 & 24.2 & \\
\hline 3.67 & 26.0 & \\
\hline 7.37 & 62 & $\delta^{18} \mathrm{O}$ dating, correlated to the LR04 stack \\
\hline 9.02 & 82 & \\
\hline 9.52 & 87 & \\
\hline 10.12 & 96 & \\
\hline 11.02 & 109 & \\
\hline 11.92 & 128 & \\
\hline 12.72 & 140 & \\
\hline 15.17 & 185 & \\
\hline 17.42 & 223 & \\
\hline 18.87 & 252 & \\
\hline 19.97 & 269 & \\
\hline 21.17 & 286 & \\
\hline 5.09 & 41 & RPI dating, correlated to the PISO-1500 stack \\
\hline 11.45 & 120 & \\
\hline 15.98 & 194 & \\
\hline 17.02 & 211 & \\
\hline 21.86 & 295 & \\
\hline 24.30 & 325 & \\
\hline 25.86 & 385 & \\
\hline
\end{tabular}

spectrum was applied to the proxies (in real data) to get a more detailed period analysis (Figs. 7b, 8b, 9b, and 10b).

As a result, variations of the $\delta^{18} \mathrm{O}$ record and its ETP curve show good correlation (Fig. 7a), revealing the dominance of the orbital forcing in environmental setting around PNG. As expected, the wavelet spectrum of the $\delta^{18} \mathrm{O}$ presents the Milankovitch periods (Fig. 7b). Also for the magnetic proxies $\left(\chi\right.$ and $\left.\chi_{\mathrm{ARM}} / \chi\right)$, the ETP curves compare well to the original records and the wavelet spectra clearly present the Milankovitch periods over the entire period of time (Figs. 8 and 9). In fact, the spectra of the other magnetic parameters (SIRM, ARM, and SIRM $/ \chi$ ) also show the dominance of the Milankovitch periods though the results are not presented in the paper.

Only the ETP curve of the S-ratio, in contrast, appears to show worse correlation to the original record; also, the spectrum presents an unusual pattern instead of showing the orbital periods (Fig. 10). The stronger signal of the S-ratio spectrum roughly centers between $\sim 40$ and $\sim 60$-ka periods before $240 \mathrm{ka}$ and shifts to $\sim 20$-ka period between 240 and $190 \mathrm{ka}$. After $190 \mathrm{ka}$, the period shifts back and centers between $\sim 40$-ka and $~ 60$-ka periods again. Moreover, instead of showing a 100-ka period, a doubtful eccentricity period is found at $\sim 130 \mathrm{ka}$, but the signal of this longer period is relatively weaker (Fig. 10b).

Except the orbital periods, we observe another feature that the spectrum signals appear to concentrate on some time periods, e.g., in MIS 7, MIS 5, and MIS 1 in the $\chi_{\mathrm{ARM}} / \chi$ record (Fig. $9 \mathrm{~b}$ ). This feature is considered to be induced by the larger changes in the original data. Huang (2010) has tested and discussed this feature and proposed that larger peaks or troughs in time series would bring significant influences to the wavelet spectrum. The amplitude would concentrate on the age when the abrupt change happened. Therefore, this feature is unrelated to the orbital forcing and is also insignificant for further environmental discussions.

Overall, the Milankovitch periods were obviously recorded in the environmental magnetic proxies except the S-ratio in the study (Figs. 7-10). Though some events with shorter periods might be unrelated to the orbital forcing, the orbital forcing undoubtedly played the key role dominating the long-term variation of the magnetic particles around PNG.

\section{Discussion}

\section{Magnetic properties related to environmental setting}

The core site of MD05-2928 is located at the southern offshore of the Papuan Peninsula (Fig. 1). At the present day, most sediments coming from central New Guinea would be stored on the inner shelf (Brunskill et al. 1995; Wolanski et al. 1995; Harris et al. 1996; Walsh et al. 2004; Keen et al. 2006). Only finer terrestrial detritus might be brought to the core site location by ocean currents. Moreover, Shiau et al. (2012) proposed that the detritus fluxes would be influenced by regional precipitation in addition to sea level or ice volume change in the area, and also, they suggested that the terrestrial detritus coming from the Papuan Peninsula would contribute a lot to the core site in colder periods based on the ${ }^{230} \mathrm{Th}$ nomalized analysis.

In the study, we provide a viewpoint from environmental magnetism. Magnetic proxies related to magnetic concentration ( $\chi$, SIRM, and ARM) show that magnetic minerals were more in glacial periods and were fewer in interglacial periods (Fig. $6 \mathrm{~b}-\mathrm{d}$ ). This property is in agreement with the general concept in passive continental margins (Nelson, 1990; Handford and Loucks, 1993; Schlager et al. 1994) and also in agreement with the 


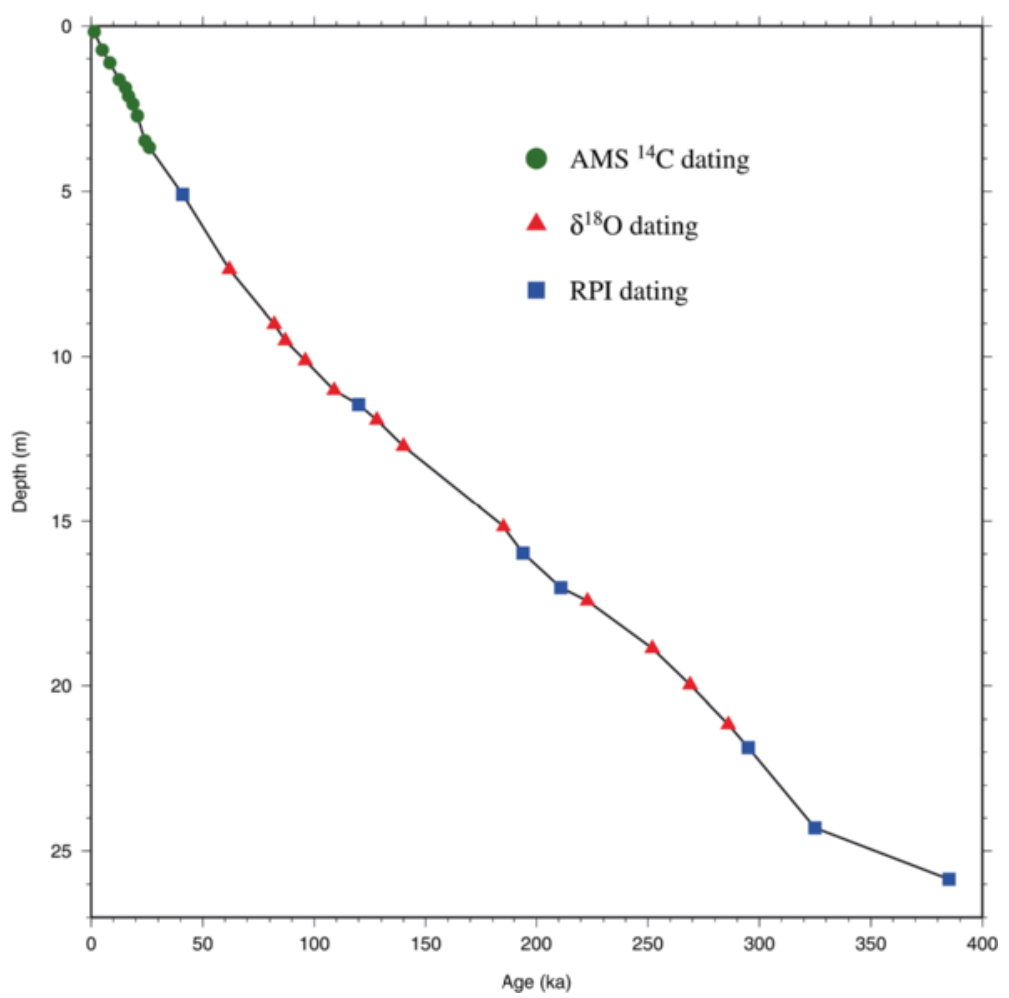

Fig. 5 Age model of the core MD05-2928. The controlling points include the AMS ${ }^{14} \mathrm{C}$ dating, $\delta{ }^{18} \mathrm{O}$ analysis, and RPI dating

studies of siliciclastic fluxes in the Pandora Trough nearby the GoP (Febo et al. 2008; Jorry et al. 2008). In addition, numerous spikes recorded in MIS 8, MIS 7.4, and MIS 6 in the $\chi$ record imply the increased input of volcanic materials in colder periods (Fig. 6b). In contrast to the $X$ and SIRM, the ARM showed relatively constant variation over the entire time period (Fig. 6d), revealing a continuous supply of finer magnetite particles for the last $400 \mathrm{ka}$. For the proxies related to the magnetic grain size $\left(\chi_{\mathrm{ARM}} / \chi\right.$ and $\left.\operatorname{SIRM} / \chi\right)$, coarser and finer grains of magnetic minerals were recorded in glacial and interglacial periods, respectively (Figs. 6e, f). The notable peaks observed in the $\chi_{\mathrm{ARM}} / \chi$ were not recorded in the SIRM/ $X$, but they occurred systematically during the periods when the $x$, SIRM, and S-ratio were low (Fig. 6). These peaks were therefore more possible to be induced by the change of the magnetic mineralogy rather than the change of the magnetic grain size.

Based on the magnetic results, possible mechanism describing the environmental setting around PNG could be interpreted: In interglacial periods, like the present day, sediments coming from the GoP would be transported by the coastal currents in the northern Coral Sea. Because coarser grain sediments were mostly stored on the shelf, only fewer and finer grain sediments would be contributed to the core site by the currents. As a result, the magnetic minerals of the core were relatively fewer and finer in interglacial periods. In glacial periods, the ocean currents might be significantly modified due to lower sea level around the area (Kuhnt et al. 2004; Holbourn et al. 2005; Huang et al. 2011). The routes of the currents regressed seaward with reduced current intensity, and therefore, the amount of sediments coming from the GoP decreased. Because sediments from the Papuan Peninsula would contribute a lot to the core site in colder periods (Shiau et al. 2012), the main source of magnetic minerals was considered to shift to the Papuan Peninsula (nearby the core site). Because the source was relatively close to the core site, the input to the core site would become more and coarser during glacial periods. In addition, the finer magnetic particles from the GoP (by the currents) should continuously contribute to the core site over the entire time period due to the evidence of the constant ARM though the amount should be relatively minor.

Because the evidence of past glaciations were also found in southeastern PNG (Hastenrath 2009), more volcanic materials from the volcanic arc (Papuan Peninsula) should be brought into the sea by glaciations in glacial periods. The signal related to the increased volcanic materials, i.e., the peaks in the $X$ record (Fig. 5b), is therefore thought to be the effect caused by stronger glaciations in colder glacial periods (MIS 8, MIS 7.4, and MIS 6). Also the result from the ${ }^{230} \mathrm{Th}$-nomalized 


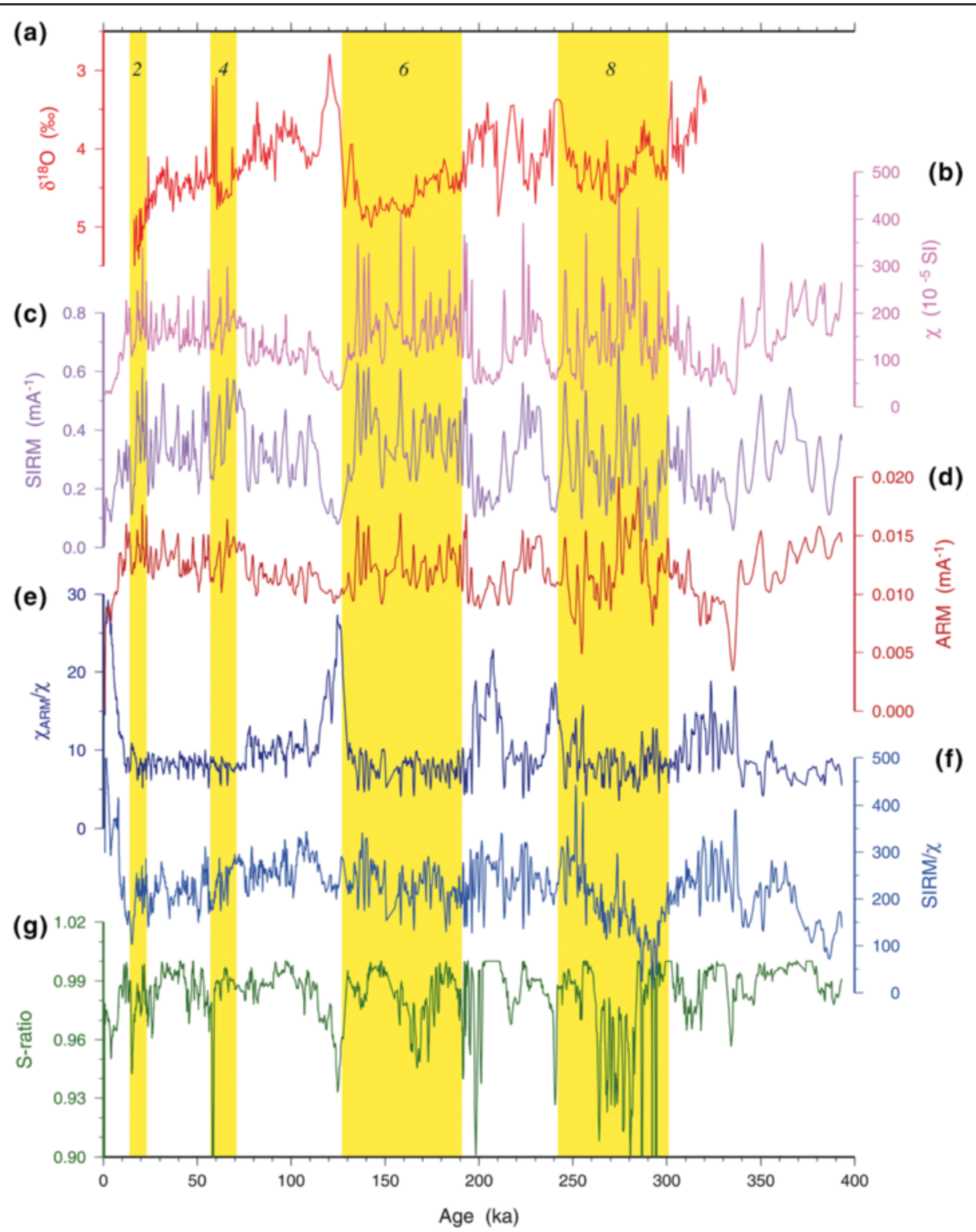

Fig. 6 Time-series data studied in the study, including (a) $\delta^{18} \mathrm{O}$, (b) magnetic susceptibility, (c) SIRM, (d) ARM, (e) $X_{\text {ARM }} / X_{1}(\mathbf{f})$ SIRM/X, and (g) S-ratio. Yellow and white areas mark the identified glacial and interglacial periods, respectively, and the numbers give the glacial stages

analysis of the core shows that the terrestrial input caused by rainfall and river runoff from the Papuan Peninsula would increase during cold periods (Shiau et al. 2012). We could therefore roughly deduce that the volcanic materials, eroded by stronger glaciations from the Papuan Peninsula, would increase and imported to the sea by rainfall and glacial meltwaters in colder glacial periods, MIS 8, MIS 7.4, and MIS 6.

As for the S-ratio of the study, the variation appears to be unrelated to the MIS change, but several low-value events are observed in glacial periods and at MIS boundaries (Fig. 6g). These events imply that stronger changes of the magnetic mineralogy, possibly related to stronger climate variation (e.g., heavy rainfall), might happen during glacial-interglacial transition. Moreover, by comparing the S-ratio with the magnetic susceptibility (Figs. 6b, g), the low-value events recorded between MIS 8 and MIS 6 could be attributed to the input of volcanic materials, which might also be influenced by the rainfall variation. Because no clear correlation between the Sratio and MIS change is observed, we think that the $\mathrm{S}$-ratio should be more sensitive to the climate variation with shorter periods in the study. These lowvalue events are preliminary attributed to the rainfall variation in PNG but more evidence is needed to improve this viewpoint. 


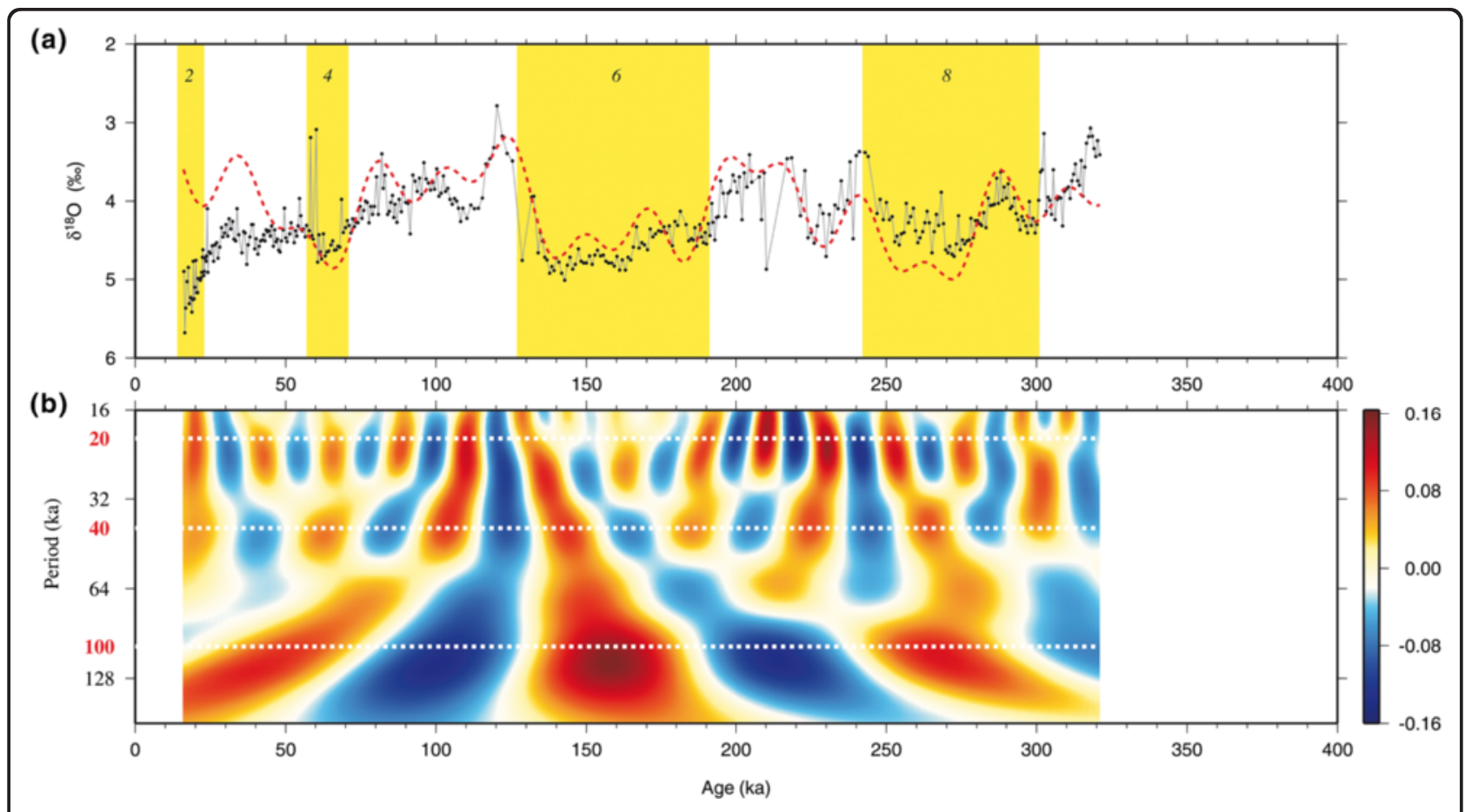

Fig. 7 a The $\delta^{18} \mathrm{O}$ data of the core MD05-2928. Red dashed line is the ETP signal of this parameter. $\mathbf{b}$ Wavelet spectrum of the $\delta^{18} \mathrm{O}$. White dashed lines show the Milankovitch periods (100, 40, and $20 \mathrm{ka})$

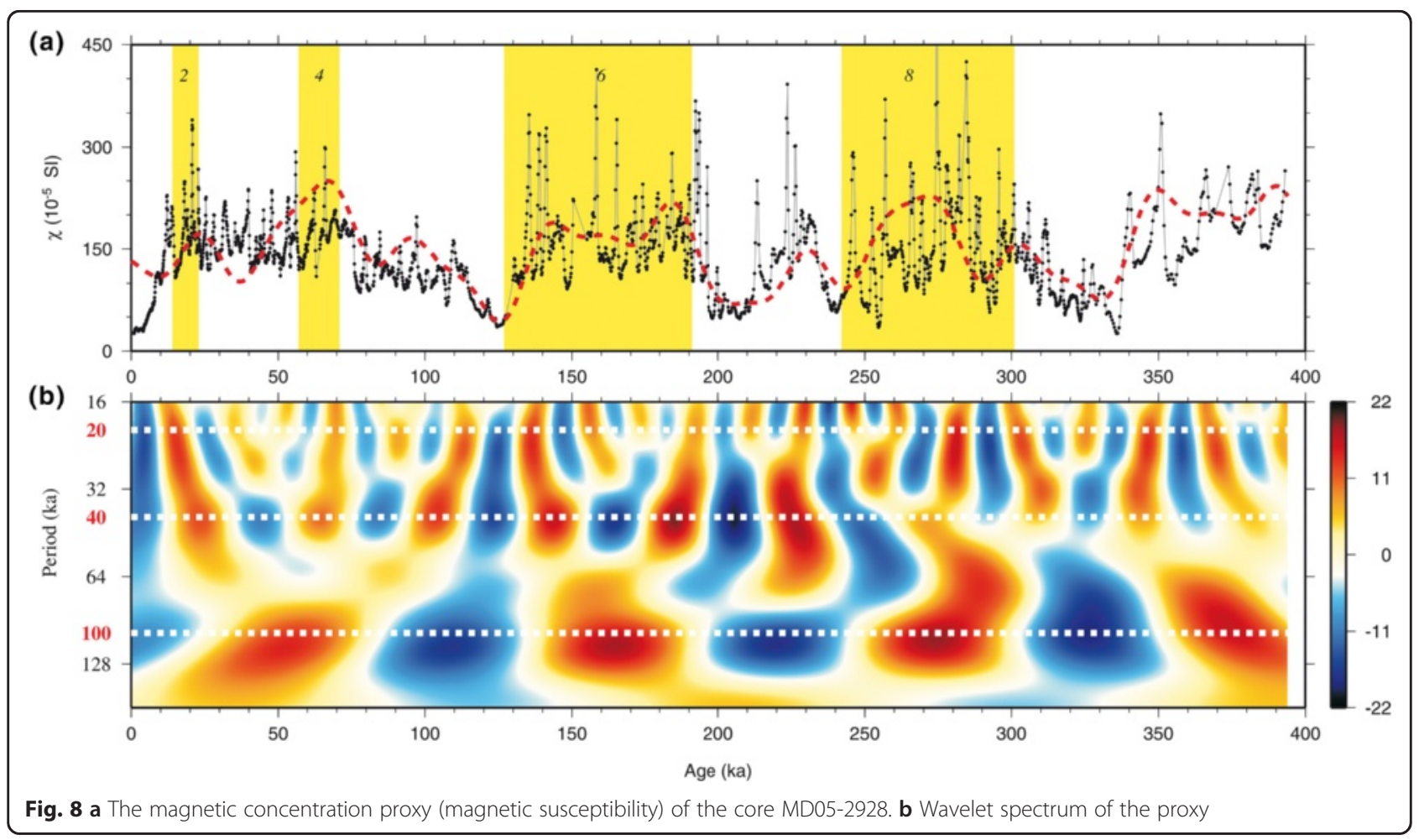




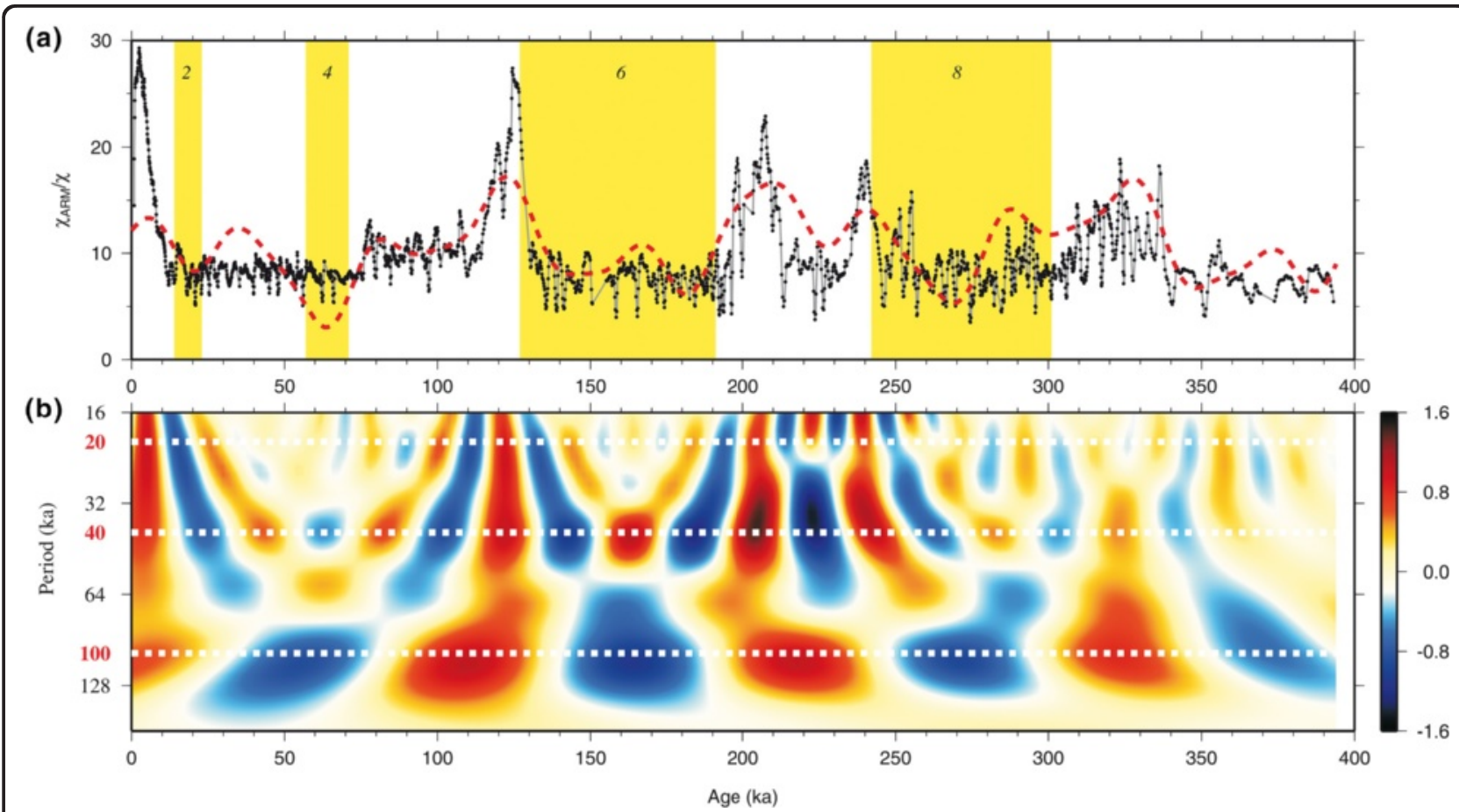

Fig. 9 a The magnetic grain size proxy $\left(X_{\text {ARM }} / X\right)$ of the core MD05-2928. b Wavelet spectrum of the proxy

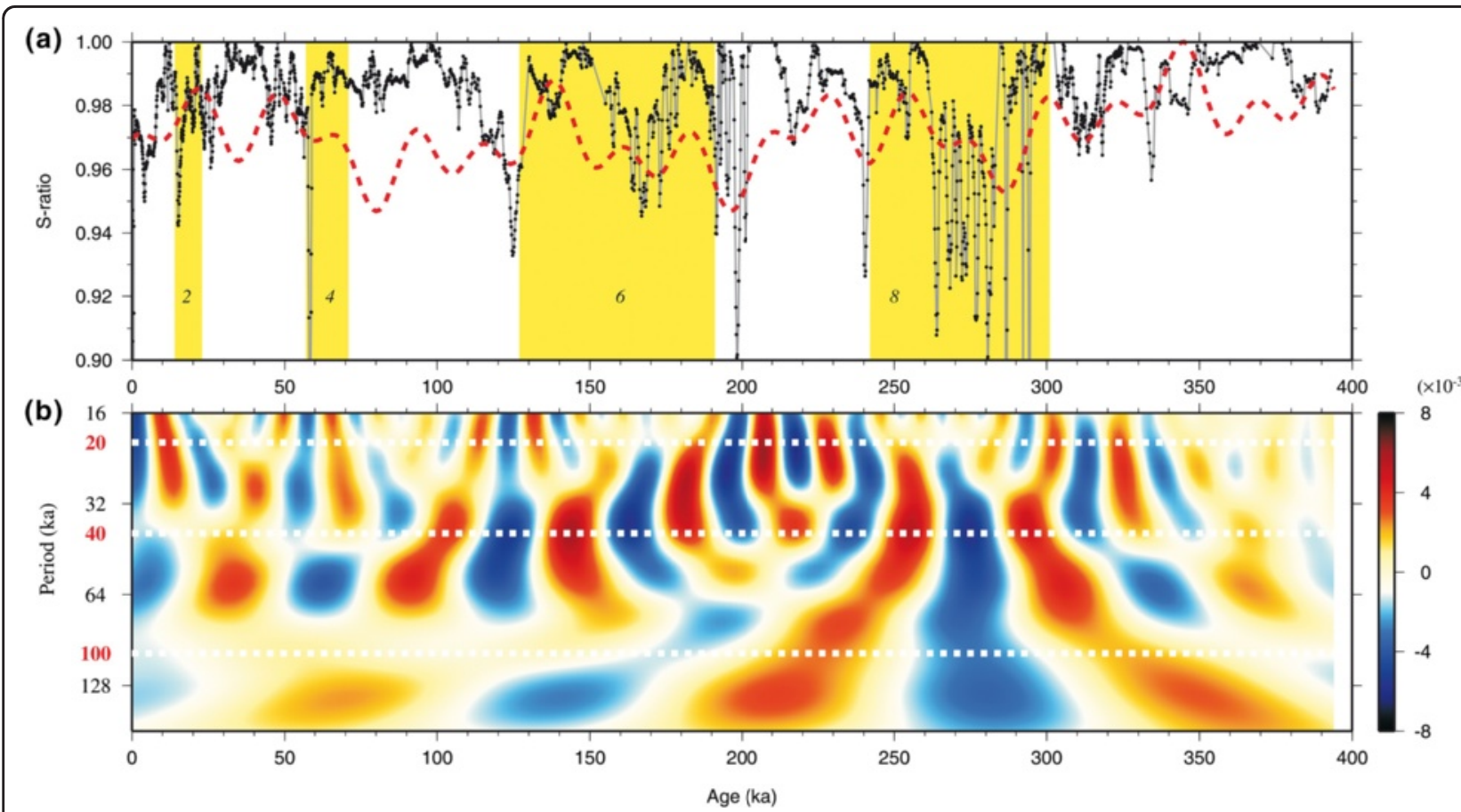

Fig. 10 a The magnetic mineralogy proxy (S-ratio) of the core MD05-2928. b Wavelet spectrum of the proxy 


\section{Dominance of the orbital forcing}

Orbital forcing has been widely demonstrated to be one of the main drivers of environmental variation. With the increase in length of sedimentary and paleoclimatic records, time scales recording the influences of orbital forcing may extend from the Quaternary to Triassic periods (e.g., Ikeda et al. 2010; Huang et al. 2011; Ikeda and Tada 2013). In general, the Milankovitch theory is conveniently used to interpret the variation of glacial and interglacial periods related to the orbital forcing. Three orbital parameters of the Milankovitch cycles are critical in describing the solar insolation change. They are eccentricity, obliquity, and precession with dominant periods centered at 100,41 , and $23 \mathrm{ka}$, respectively. The 100-ka period, also thought to be main MIS cycle (Broecker and van Donk 1970), is usually related to global ice volume accumulation and/or sea level change. The 41 and 23 ka periods, possibly linked more to the solar insolation change (Muller and MacDonald 2000), might control the amount of regional precipitation.

Based on the results of the magnetic properties, sea level change is suggested to be an important factor affecting the long-term environmental variation around PNG. In the periodicity study, both analyses of ETP curves and wavelet spectra of the parameters show the dominance of orbital forcing except the S-ratio (Figs. 710). The presence of the strongest 100-ka signal may also give the evidence to our suggestion: Long-term variations of the magnetic concentration (the proxy $X$ ) and magnetic grain size (the proxy $\chi_{\mathrm{ARM}} / \chi$ ) were dominated by the changed route and intensity of the costal currents due to sea level change. Sea level change should certainly be the key role controlling the environmental setting around PNG.

In addition, both 40- and 20-ka periods are also significant in the spectra (Figs. 7b-9b), indicating the importance of the effects from obliquity and precession though the 20-ka signal appears to be relatively weaker. Obliquity and precession are generally considered to be more related to the solar insolation. Increased/decreased solar insolation would raise/reduce the temperature and then supplied more/fewer water vapors to the atmosphere; as a result, more/less rainfall would be received in PNG. The study of the detritus flux proxies of this core also suggested that the 20-ka components should be attributed to regional precipitation (Shiau et al. 2012). Therefore, in addition to global sea level change, the precipitation variation should be the second factor affecting the environmental setting around PNG.

Instead of showing the typical Milankovitch periods, the spectrum of the S-ratio, generally thought to be related to the change of magnetic mineralogy, presents an unusual pattern. Dominant signal appears to vary between $\sim 60$ - and $\sim 20-\mathrm{ka}$ periods (Fig. 10b), probably resulting from the interaction between obliquity and precession. We might therefore suggest that the S-ratio should be a proxy more sensitive to obliquity and precession in the study. However, the mechanism between the change of magnetic mineralogy and the change of regional precipitation, which might be linked to the solar insolation variation, is still unknown at this step. More records and evidences are needed to improve the viewpoint.

\section{Conclusions}

The core MD05-2928, with $26.1 \mathrm{~m}$ in length, covers an age period over the past $\sim 400 \mathrm{ka}$. From the magnetic results of the core, we can observe that variations of magnetic parameters $\left(\chi, \operatorname{SIRM}, \mathrm{ARM}, \chi_{\mathrm{ARM}} / \chi\right.$, and SIRM $/ \chi$ ) are clearly related to the MIS change. This feature denotes that these magnetic parameters could be considered as proxies describing the paleoenvironmental variation around PNG. In interglacial periods, sediments coming from New Guinea and the GoP would be imported to the sea and then transported by the coastal currents in northern Coral Sea. Coarser sediments would be stored on the shelf, and only fewer and finer sediments were contributed to the core site by the currents. As a result, magnetic minerals of the core were fewer and finer in interglacial periods. In glacial periods, the routes of the coastal currents possibly regressed seaward with reduced current intensity due to the lower sea level. Sediments coming from the GoP should decrease, and main source might shift to the Papuan Peninsula. Because the sediment source from the Papuan Peninsula was relatively near the core site, magnetic minerals became more and coarser in glacial periods. Moreover, the ETP curves and wavelet spectra clearly show the dominance of the Milankovitch periods. The strongest signal of $100-\mathrm{ka}$ period reveals that sea level change dominates the long-term environmental setting around PNG. However, effects from the orbital forcing of 40- and 20-ka periods, possibly related more to the solar insolation variation, should also be considered even though they might be second factors affecting the environmental setting around PNG.

\section{Competing interests}

The authors declare that they have no competing interests.

\section{Authors' contributions}

YSH did the magnetic measurements, ran the data analyses, and drafted the manuscript. TQL collected and provided the core sample. TQL and SKH funded the plan, and also they raised critical issues in the first draft. All authors read and approved the final manuscript.

\section{Acknowledgements}

We would like to express our appreciation to all the researchers and staffs on the R.V. Marion Dufresne operated by the French Polar Institute (IPEV) during the IMAGES Cruise VII to collect such a high quality core from the Coral Sea. We particularly thank Dr. Yu-Min Chou, National Taiwan University (NTU) for his great help in FORC measurements and giving us lots of valuable comments. Also we would like to thank the group of the national core laboratory located at the National Taiwan Ocean University (NTOU) for the help of the core sampling; members in the paleomagnetic laboratory, institute of Earth Sciences (IES), Academia Sinica for the help on the 
magnetic experiments; and crew of marine geophysical research, National Central University (NCU) for valuable discussions. The financial support came from National Science Council (NSC) of Taiwan under the grant NSC 95-2116-M-001-011. The figures were mainly plotted by using GMT software (Wessel and Smith 1998), and the calculation was done by using MATLAB software.

\section{Received: 30 January 2015 Accepted: 3 August 2015} Published online: 14 August 2015

\section{References}

Bassett SE, Milne GA, Mitrovica JX, Clark PU (2005) Ice sheet and solid earth influences on far-field sea-level histories. Science 309:925-928

Beaufort L, Chen MT, Droxler AW, Yokoyama Y, Balut Y, Rothe S (2005) MD148-PECTEN IMAGES XIII cruise report. Inst. Pol. Fr, Plouzane, France

Broecker WS, van Donk J (1970) Insolation changes, ice volumes, and the $\delta^{18} \mathrm{O}$ record in deep-sea cores. Rev Geophys Space Phys 8:169-197

Brunskill GJ, Woolfe KJ, Zagorskis I (1995) Distribution of riverine sediment chemistry on the shelf, slope and rise of the Gulf of Papua. Geo Mar Lett 15:160-165

Brunskill GJ (2004) New Guinea and its coastal seas, a testable model of wet tropical coastal processes: an introduction to Project TROPICS. Cont Shelf Res 24:2273-2295

Carson BE, Francis JM, Leckie RM, Droxler AW, Dickens GR, Jorry SJ, Bentley SJ, Peterson LC, Opdyke BN (2008) Benthic Foraminiferal response to sea level change in the mixed siliciclastic-carbonate system of southern Ashmore Trough (Gulf of Papua). J Geophy Res 113:F01S20. doi:10.1029/2006JF000629

Channell JET, Xuan C, Hodell DA (2009) Stacking paleointensity and oxygen isotope data for the last 1.5 Myr (PISO-1500). Earth Planet. Sci Lett 283:14-23

Chao BF, Naito I (1995) Wavelet analysis provides a new tool for studying earth's rotation. Eos, Trans. AGU 76:161-165

Clark PU, Marshall A, McCabe A, Mix AC, Weaver J (2004) Rapid rise of sea level 19000 years ago and its global implications. Science 304:1141-1144

Dunbar GB, Dickens GR, Carter RM (2000) Sediment flux across the Great Barrier Reef Shelf to the Queensland Trough over the last 300 ky. Sediment Geol 133:49-92

Egli R (2006) Theoretical aspects of dipolar interactions and their appearance in first-order reversal curves of thermally activated single-domain particles. J Geophys Res 111:B12S17. doi:10.1029/2006JB004567

Egli R, Chen AP, Winklhofer M, Kodama KP, Horng CS (2010) Detection of noninteracting single domain particles using first-order reversal curve diagrams. Geochem Geophys Geosyst 11:Q01Z11. doi:10.1029/2009GC002916

Febo LA, Bentley SJ, Wrenn JH, Droxler AW, Dickens GR, Peterson LC, Opdyke BN (2008) Late Pleistocene and Holocene sedimentation, organic-carbon delivery, and paleoclimatic inferences on the continental slope of the northern Pandora Trough, Gulf of Papua. J Geophy Res 113:F01S18

Guyodo Y, Valet JP (1999) Global changes in intensity of the Earth's magnetic field during the pass 800 kyr. Nature 399:249-252

Handford CR, Loucks RG (1993) Carbonate depositional sequences and system tracts-Responses of carbonate platforms to relative sea-level changes. In Carbonate Sequence Stratigraphy: Recent Developments and Application. Loucks RG, Sarg JF (eds). AAPG Mem 57:3-41

Harris PT, Pattiaratchi CB, Keene JB, Dalrymple RW, Gardner JV, Baker EK, Cole AR, Mitchell D, Gibbs P, Schroeder WW (1996) Late Quaternary deltaic and carbonate sedimentation in the Gulf of Papua foreland basin: response to sea-level change. J Sediment Res 66:801-819

Harrison RJ, Feinberg JM (2008) FORCinel: an improved algorithm for calculating first-order reversal curve distributions using locally weighted regression smoothing. Geochem Geophys Geosyst 9, Q05016

Hastenrath S (2009) Past glaciation in the tropics. Quat Sci Rev 28(9-10):790-798

Heslop D, Roberts AP, Chang L, Davies M, Abrajevitch A, De Deckker P (2013) Quantifying magnetite magnetofossil contributions to sedimentary magnetizations. Earth Planet Sci Lett 382:58-65

Hobbs JE, Lindesay JA, Bridgman HA (1998) Climates of the southern continents: present, past and future. West Sussex, England, John Wiley \& Sons Ltd

Holbourn A, Kuhnt W, Kawamura H, Jian Z, Grootes P, Erlenkeuser H, Xu J (2005) Orbitally paced paleoproductively variations in the Timor Sea and Indonesian Throughflow variability during the last 460 kry.

Paleoceanography 20, PA3002
Huang YS (2010) Late Quaternary Milankovitch-scale environmental variation in the western Pacific: time-series analysis of magnetic data, $\mathrm{PhD}$ thesis. National Central University, Chung-Li, Taiwan

Huang YS, Lee TQ, Hsu SK (2011) Milankovitch-scale environmental variation in the Banda Sea over the past 820 ka: fluctuation of the Indonesian through flow intensity. J Asian Earth Sci 40:1180-1188

Ikeda M, Tada R, Sakuma H (2010) Astronomical cycle origin of bedded chert: a middle Triassic bedded chert sequence, Inuyama, Japan. Earth Planet Sci Lett 297:369-378

Ikeda M, Tada R (2013) Long period astronomical cycles from the Triassic to Jurassic bedded chert sequence (Inuyama, Japan); geologic evidences for the chaotic behavior of solar planets. Earth Planet Space 65:351-360

Jorry SJ, Droxler AW, Mallarino G, Dickens GR, Bentley SJ, Beaufort L, Peterson LC, Opdyke BN (2008) Bundled turbidite deposition in the central Pandora Trough (Gulf of Papua) since Last Glacial Maximum: linking sediment nature and accumulation to sea level fluctuations at millennial timescale. J Geophy Res 113:F01S19. doi:10.1029/2006JF000649

King J, Banerjee SK, Marvin J, Ozdemir O (1982) A comparison of different magnetic methods for determining the relative grain size of magnetite in nature materials: some results from lake sediments. Earth Planet Sci Lett 59:404-419

King JW, Banerjee SK, Marvin J (1983) A new rockmagnetic approach to selecting sediments for geomagnetic paleointensity studies: application to paleointensity for the last 4000 years. J Geophy Res 88:5911-5921

Keen TR, Ko DS, Slingerland RL, Riedlinger S, Flynn P (2006) Potential transport pathways of terrigenous material in the Gulf of Papua. Geophys Res Lett 33:L04608

Kuhnt W, Holbourn AE, Hall R, Zuleva M, Kase R (2004) New history of the Indonesia Throughflow. In Continent-Ocean Interations Within East Asia Marginal Seas. Geophys Monogr Ser 149:287-308, AGU, Washington D. C

Lisiecki LE, Raymo ME (2005) A Pliocene-Pleistocene stack of 57 globally distributed benthic $\delta^{18} \mathrm{O}$ records. Paleoceanography 20, PA1003

Liu HS, Chao BF (1998) Wavelet spectral of the earth's orbital variation an paleoclimate cycles. J Atmos Sci 55:227-236

McAlpine JR, Keig G, Falls R (1983) Climate of Papua New Guinea. CSIRO and Australian National University Press, Canberra, Australia

Milliman JD (1995) Sediment discharge to the ocean from small mountainous rivers: the New Guinea example. Geo Mar Lett 15(3-4):127-133

Morlet J, Arehs I, Fourgeau I, Giard D (1982) Wave propagation and sampling theory. Geophysics 47:203-236

Moskowitz BM, Frankel RB, Bazylinski DA (1993) Rock magnetic criteria for the detection of biogenic magnetite. Earth Planet Sci Lett 120:283-300

Muhammad Z, Bentley SJ, Febo LA, Droxler AW, Dickens GR, Peterson LC, Opdyke BN (2008) Excess ${ }^{210} \mathrm{~Pb}$ inventories and fluxes along the continetal slope and bassins of the Gulf of Papua. J Geophy Res 113:F01S17

Muller RA, MacDonald GJ (2000) Ice ages and astronomical causes: data, spectral analysis and mechanisms. Chichester, UK, Springer-PRAXIS

Nelson CH (1990) Estimated post-Messinian sediment supply and sedimentation rates on Ebro continental margin, Spain. Marine Geology 95:395-418

Opdyke ND, Channell JET (1996) Magnetic parameters sensitive to concentration, grain size and mineralogy. In: Magnetic stratigraphy. Academic, USA, pp 251-253

Page MC, Dickens GR, Dunber GB (2003) Tropical view of quaternary sequence stratigraphy: siliciclastic accumulation on slopes east of the Great Barrier Reef since the Last Glacial Maximum. Geology 31:1013-1016

Pike CR, Roberts AP, Verosub KL (1999) Characterizing interactions in fine magnetic particle systems using first order reversal curves. J Appl Phys 85:6660-6667

Qu T, Lindstrom EJ (2002) A climatological interpretation of the circulation in the western south Pacific. J Phys Oceanogr 32:2492-2508

Roberts AP, Pike CR, Verosub KL (2000) First-order reversal curve diagrams: a new tool for characterizing the magnetic properties of natural samples. J Geophys Res 105:28,461-28,475

Shiau L, Chen MT, Clemens SC, Huh CA, Yamamoto M, Yokoyama Y (2011) Warm pool hydrological and terrestrial variability near southern Papua New Guinea over the past 50k. Geophys Res Lett 38:L00F01

Shiau LJ, Chen MT, Huh CA, Yamamoto M, Yokoyama Y (2012) Insolation and cross-hemispheric controls on Australian monsoon variability over the past 180 ka: new evidence from offshore southeastern Papua New Guinea. J Quarter Sci 27:911-920

Schlager W, Reijmer JJG, Droxler AW (1994) Highstand shedding of carbonate platforms. J Sediment Res 64:270-28 
Sugiura N (1979) ARM, TRM, and magnetic interactions: concentration dependence. Earth Planet Sci Lett 42:451-455

Tauxe L (1993) Sedimentary records of relative paleointensity of the geomagnetic field: theory and practice. Rev Geophys 31(3):319-354

Tric E, Valet JP, Tucholka P, Paterne M, Labeyrie L, Guichard F, Tauxe L, Fontugne M (1992) Paleointensity of the geomagnetic field during the last 80,000 years. J Geophys Res 97(B6):9337-9351

Valet JP, Maynadier L, Guyodo Y (2005) Geomagnetic dipole strength and reversal rate over the past two million years. Nature 435:802-805

Walsh JP, Nittrouer CA (2003) Contrasting styles of off-shore sediment accumulation in New Guinea. Mar Geol 196:105-125

Walsh JP, Nittrouer CA, Palinkas CM, Ogston AS, Sternberg RW, Brunskill GJ (2004) Clinoform mechanics in the Gulf of Papua, New Guinea. Cont Shelf Res 24:2487-2510

Wang PS (2009) Global monsoon in a geological perspective. Chinese Sci Bull 54(7):1113-1136

Wessel P, Smith WHF (1998) New improved version of Generic Mapping Tools released, EOS Trans. AGU 79:579

Wolanski E, Norro A, King B (1995) Water circulation in the Gulf of Papua. Cont Shelf Res 15:185-212

Yamazaki T, Oda H (2005) A geomagnetic paleointensity stack between 0.8 and 3.0 Ma from equatorial Pacific sediment cores. Geochem Geophys Geosyst 6:Q11H20

Yan XH, Ho CR, Zheng Q, Klemas V (1992) Temperature and size variabilities of the western Pacific warm pool. Science 258:1643-1645

Yokoyama Y, Lambeck K, De Deckker P, Johnson P, Fifield K (2000) Timing of the Last Glacial Maximum from observed sea-level minima. Nature 406:713-716

\section{Submit your manuscript to a SpringerOpen ${ }^{\circ}$ journal and benefit from:}

- Convenient online submission

- Rigorous peer review

- Immediate publication on acceptance

- Open access: articles freely available online

- High visibility within the field

- Retaining the copyright to your article

Submit your next manuscript at $>$ springeropen.com 